\title{
Anatomy of the Great Posterior Radiculomedullary Artery
}

\author{
(D) V.H. Perez Perez, (D). Hernesniemi, and (D).E. Small
}

\begin{abstract}
BACKGROUND AND PURPOSE: Although considerable variability exists as to the overall caliber of radiculomedullary arteries, dominant radiculomedullary arteries such as the artery of Adamkiewicz exist. The existence of a great posterior radiculomedullary artery has attracted little attention and has been a matter of debate. The aim of this anatomic study was to determine the presence or absence of the great posterior radiculomedullary artery.
\end{abstract}

MATERIALS AND METHODS: We performed microsurgical dissection on formaldehyde-fixed cadaveric human spinal cords. The artery of Adamkiewicz in the spinal cord specimens $(n=50)$ was injected with colored latex until the small-caliber arterial vessels were filled and the great posterior radiculomedullary artery was identified. The course, diameter, and location of great posterior radiculomedullary artery were documented.

RESULTS: A great posterior radiculomedullary artery was identified in 36 (72\%) spinal cord specimens. In 11 (22\%) specimens, bilateral great posterior radiculomedullary arteries were present. In 13 cases (26\%), a unilateral left-sided great posterior radiculomedullary artery was identified. In 11 cases (22\%), a unilateral right-sided great posterior radiculomedullary artery was identified. In 1 specimen (2\%), 3 right-sided great posterior radiculomedullary arteries were noted. The average size of the great posterior radiculomedullary arteries was $0.44 \mathrm{~mm}$ (range, $0.120-0.678 \mathrm{~mm}$ on the left and $0.260-0.635 \mathrm{~mm}$ on the right).

CONCLUSIONS: A great posterior radiculomedullary artery is present in most (72\%) individuals. The authors describe the microsurgical anatomy of the great posterior radiculomedullary artery with emphasis on its morphometric parameters as well as its implications for spinal cord blood supply. Variations of the arterial supply to the dorsal cord are of great importance due to their implications for ischemic events, endovascular procedures, and surgical approaches.

ABBREVIATIONS: AKA = artery of Adamkiewicz; ASA = anterior spinal artery; GPRA = great posterior radiculomedullary artery; PSA = posterior spinal artery

$\mathbf{U}^{\prime}$ nderstanding the basic vascular anatomy of the spinal cord is of utmost importance for imaging interpretation and endovascular and surgical management of spinal cord vascular malformations. Advances in diagnostic and therapeutic interventions have led to a need for more detailed and specific understanding of the microvasculature of the spinal cord. In particular,

Received August 28, 2019; accepted after revision September 19.

From the Department of Neurosurgery (V.H.P.P.), Instituto de Ciencias Forenses, TSJ Ciudad de México, Centro Medico Siglo XXI, Mexico City, Mexico; Department of Neurosurgery (J.H.), International Center for Neurosurgery, Henan Provincial People's Hospital, Zhengzhou, China; and Department of Radiology (J.E.S.), Neuroradiology Section, Lahey Hospital and Medical Center, Burlington, Massachusetts.

Paper previously presented as an oral presentation at: Annual Meeting of the American Society of Neuroradiology, May 18-23, 2019; Boston, Massachusetts.

Please address correspondence to Juan E. Small, MD, MSc, Department of Radiology, Lahey Hospital \& Medical Center, 41 Mall Road, Burlington, MA 01805; e-mail: Juan.E.Small@Lahey.org

http://dx.doi.org/10.3174/ajnr.A6304 attention to the anatomic variations of the smaller caliber circulatory supply to the spinal cord allows tailored management of a specific patient.

At its most basic, the spinal cord derives circulatory supply from 1 ventral (anterior spinal artery) and 2 dorsal (posterior spinal arteries) arterial trunks. The anterior spinal artery (ASA) courses along the anterior sulcus of the spinal cord and supplies the anterior two-thirds of the spinal cord (including the anterior horns and spinothalamic and corticospinal tracts). The ASA exhibits a variable caliber along its course, ranging in size from 0.2 to $0.8 \mathrm{~mm} .{ }^{1,2}$ The pair of posterior spinal arteries (PSAs) courses along the posterolateral surface of the spinal cord. The PSAs generally have a caliber of $0.1-0.4 \mathrm{~mm}^{2,3}$ and supply the posterior third of the spinal cord (including the posterior columns, dorsal gray matter, and superficial dorsal aspect of the lateral columns).

A variable number of radicular arteries originating from segmental arteries or homologous vessels make arterial contributions 


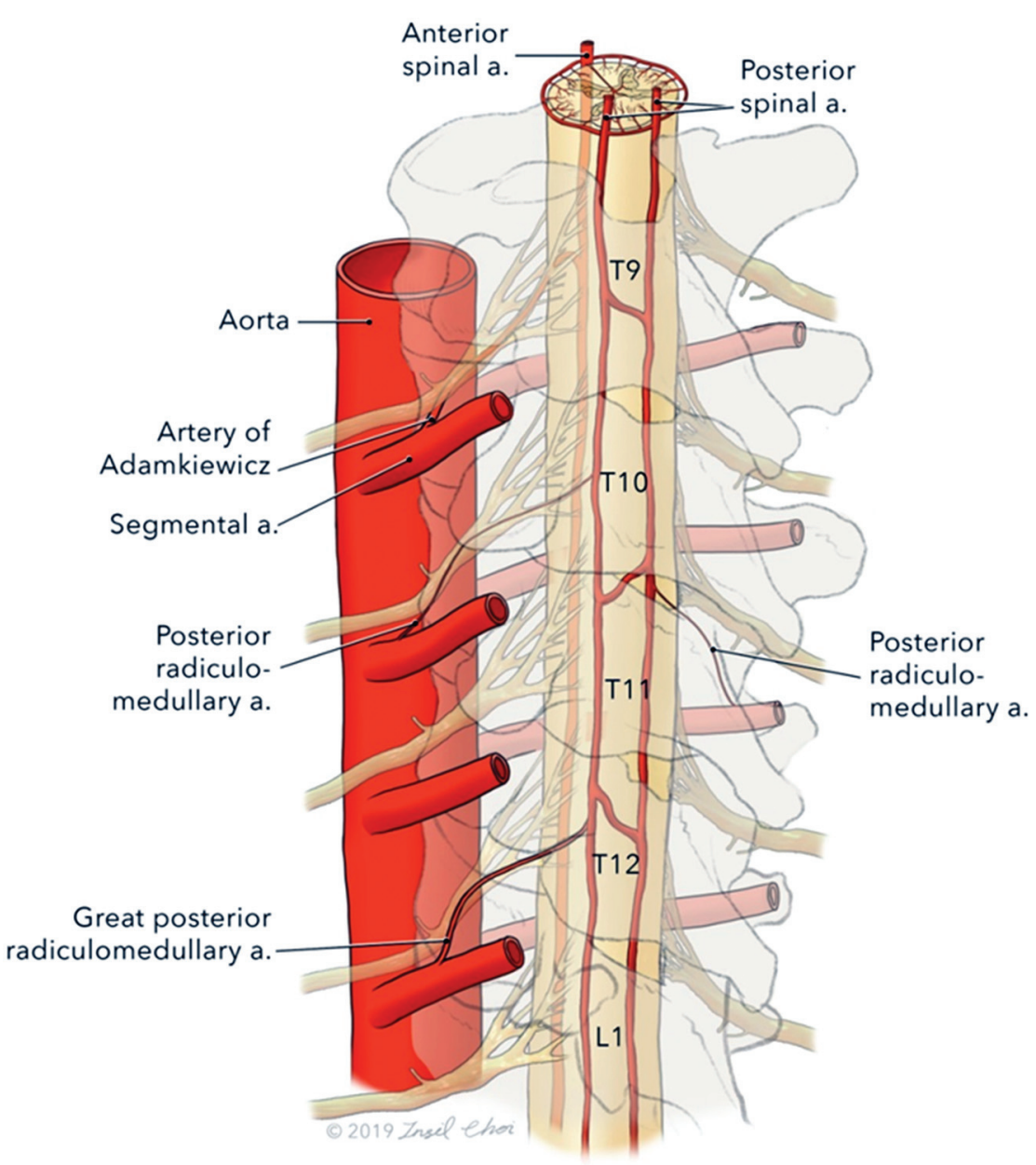

FIG 1. Illustration of the arterial radiculomedullary supply to the spinal cord. A posterior view of the distal spinal cord demonstrates the radiculomedullary supply of the distal cord. Ventrally, the artery of Adamkiewicz can be seen as the dominant anterior radiculomedullary supply. A dominant posterior radiculomedullary arterial feeder is referred to as the great posterior radiculomedullary artery. Image ๑ 2019 Insil Choi. Reproduced with permission.

as lateral feeders along the course of the spine. These radicular arteries are of small-but-differing calibers. Most of these radicular arteries supply nerve roots, the dura, or the pial plexus. Only a few of these radicular arteries specifically provide arterial supply to the collateral network of vessels supplying the spinal cord. ${ }^{4,5}$ These vessels are specifically termed radiculomedullary arteries. Radicular branches contributing to the ASA are referred to as anterior radiculomedullary arteries. The paired posterior spinal arteries are supplied by the posterior radiculomedullary arteries. The variability in number, caliber, and entrance level of anterior and posterior radiculomedullary arteries has been studied. ${ }^{6-8}$ The number of anterior radiculomedullary arteries ranges from 2 to $14 .^{1}$ Approximately 11-16 radiculomedullary arteries supply the PSAs along their course. ${ }^{1}$ The collateral network established by the anterior and posterior radiculomedullary arteries aids in spinal cord perfusion by allowing the redundancy of an anastamotic network of vessels. In this sense, the anterior and posterolateral spinal arteries are not typical arteries. They are, instead, systems of longitudinal anastomoses connecting with ascending and descending radiculomedullary artery branches. ${ }^{3}$

An inverse correlation between the caliber and number of anterior radiculomedullary vessels supplying the entire spinal cord has been described. ${ }^{6,8}$ When few in number (2-5), they are referred to as a pauci-segmental type with larger caliber vessels. When they number at least 6 , they are referred to as a pluri-segmental type with smaller caliber vessels. $^{3}$

Although variability exists as to the overall caliber of radiculomedullary arteries, dominant radiculomedullary arteries are present. The most important radiculomedullary artery is the arteria radicularis magna, otherwise known as the artery of Adamkiewicz (AKA). The AKA arises in the thoracolumbar region between $\mathrm{T} 8$ and $\mathrm{L} 2$ in 75\% of patients and has a diameter of $0.5-1.2 \mathrm{~mm}^{1,2}$

The arterial supply to the posterior spinal arteries has attracted considerably less attention compared with the anterior spinal arterial supply. Because the posterior vessels are considerably smaller in diameter, they are difficult to identify on angiography and very few studies have analyzed their lumbosacral anatomy in cadavers. The arterial radiculomedullary supply to the posterior spinal system in the region of the AKA often includes 2 dorsal feeders of similar caliber, generally 400$500 \mu \mathrm{m} .^{3}$ The existence of a great posterior radiculomedullary artery (GPRA) has been a matter of debate (Fig 1). The presence of such an artery corresponding with the AKA, with a distinctly greater caliber than other posterior radiculomedullary arteries, has been acknowledged by a few authors ${ }^{3,5,7,8}$ but denied by others. $^{8-10}$

The aim of this anatomic study was to analyze the lumbosacral arterial supply to the dorsal spinal cord and determine the presence or absence of the GPRA. In addition, we set out to analyze its morphometric characteristics.

\section{MATERIALS AND METHODS}

We conducted an institutional review board-approved study of 50 (49 men and 1 woman) unembalmed cadaveric specimens at the Institute of Forensic Sciences of Mexico City (Instituto de Ciencias Forenses de la Ciudad de Mexico). Specimens with any spinal pathology were excluded from the analysis. The cadavers ranged in age from 20 to 70 years (median age, 40 years). The 

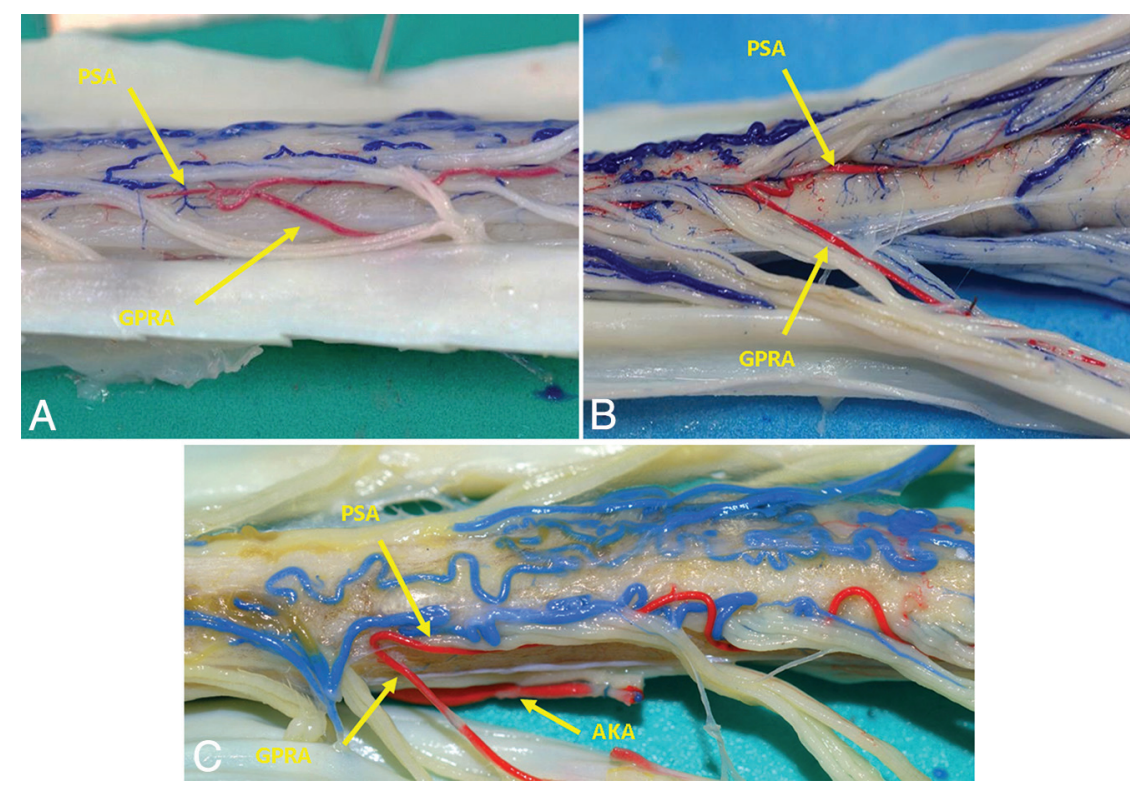

FIG 2. The great posterior radiculomedullary artery. Dorsolateral views from 3 different spinal cord specimens $(A-C)$ reveal clear evidence of a dominant GPRA.
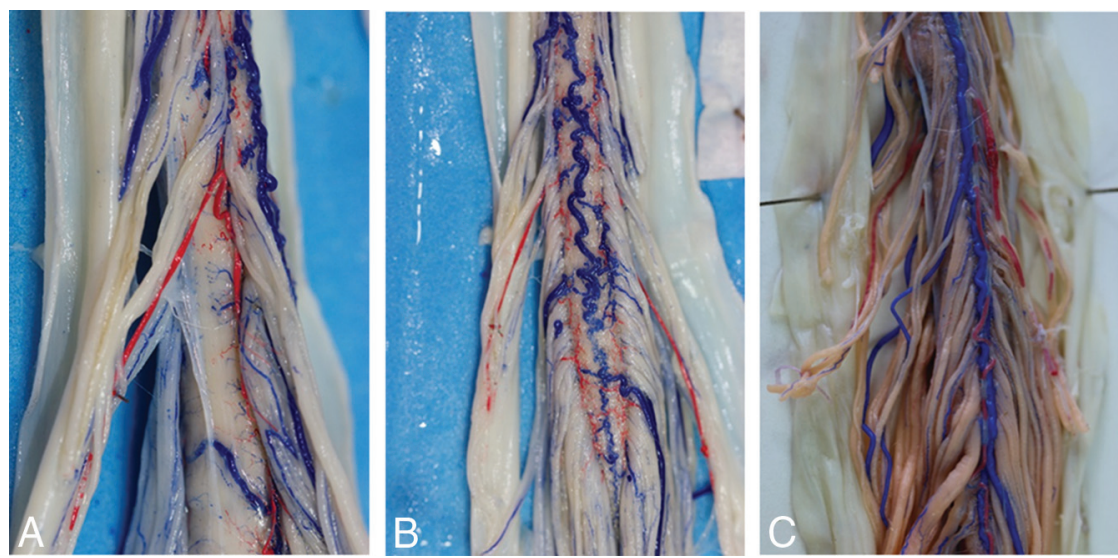

FIG 3. GPRA position. Photographs of the posterior aspect of the spinal cord in 3 different specimens show a left-sided GPRA ( $A$ ), bilateral GPRAs ( $B$ ), and a right-sided GPRA (C). A unilateral leftsided GPRA was seen in $13(26 \%)$ specimens; a unilateral right sided GPRA, in 11 cases (22\%); and bilateral GPRAs, in 11 specimens (22\%).

spinal cords were extracted via a longitudinal midline posterior incision from the occiput to the sacrum. Anatomic dissection was performed until reaching the vertebral lamina. Laminectomies were performed from $\mathrm{C} 1$ to $\mathrm{L} 5$. The spinal nerves were cut with care so as not to lesion the dura. With the use of surgical loupes, ventral and dorsal longitudinal midline durotomies were performed. The spinal cord was irrigated with saline. The vascular system was irrigated with saline to purge residual blood and blood clots. The AKA was identified and cannulated with an angiocatheter of commensurate size. Red natural latex was injected into the AKA under moderate pressure and close visual inspection to avoid contrast extravasation. The injection was continued until latex filled distal small caliber arterial vessels, including the posterior spinal arteries. Veins were injected with blue natural latex. No evidence of spinal cord pathology, including vascular malformations or fistulas, was identified in any of the samples included in this analysis. The specimens were then fixed in a $5 \%$ formaldehyde solution. Two weeks after fixation, the spinal cord specimens were studied with surgical loupes $(5 \times)$. We identified the artery of Adamkiewicz as well as the major posterior arterial radicular arteries. We conducted measurements with digital Vernier calipers in conjunction with digital measurements of computerized photographic images with a scale included in the photographic image. In particular, we searched for the presence or absence of the GPRA.

\section{RESULTS}

A GPRA was identified in $72 \%$ of spinal cord specimens (36/50) (Fig 2). This total included specimens in which unilateral and bilateral GPRAs were found, as well as a single case in which 3 GPRAs were evident. In $26 \%$ of the specimens, a unilateral left-sided GPRA was present (13/50). A unilateral right-sided GPRA was present in $22 \%$ of the specimens $(11 / 50)$. In $22 \%$ of the specimens, bilateral GPRAs were present (11/50) (Fig 3). One specimen demonstrated 3 right-sided GPRAs (Fig 4). The laterality and spinal level of GPRAs are summarized in Table 1. Including unilateral and bilateral specimens, a total of 24 GPRAs were present on the left extending from T9 through L2. Including unilateral, bilateral, and triplicated specimens, a total of 25 right-sided GPRAs were present with their distribution ranging from T9 through L3. A GPRA was most frequently identified at the level of T12, with 9 left- and 9 right-sided specimens identified at this level. Of the 11 specimens with bilateral GPRAs, 8 demonstrated GPRAs at the same level (most often T12).

Average GPRA size was $0.44 \mathrm{~mm}$ with a range of 0.120 $0.678 \mathrm{~mm}$ on the left and $0.260-0.635 \mathrm{~mm}$ on the right. Although the caliber of the GPRAs did not approximate that of the AKA, the vessels were truly dominant and easily distinguished from the tiny caliber of the radicular arteries, which accompany posterior spinal nerves. In the specimen that demonstrated 3 right-sided GPRAs, they were seen at T11 $(0.371 \mathrm{~mm})$, T12 $(0.319 \mathrm{~mm})$, and L1 $(0.240 \mathrm{~mm})$. Of note, no absolute cutoff measurement was used to establish the presence of a GPRA because establishing the presence of a dominant arterial feeder is a relative process specific to each patient. For instance, the pauci-segmental and pluri- 


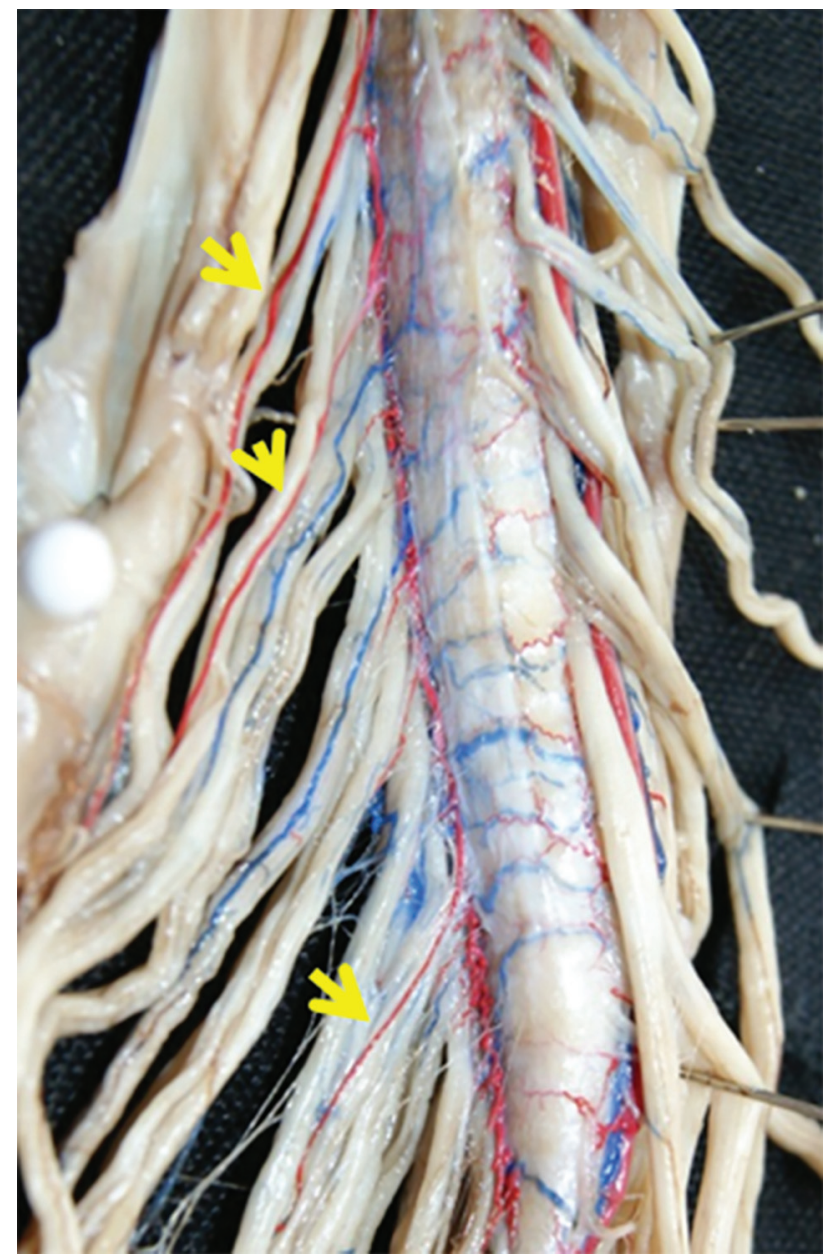

FIG 4. Multiple GPRAs. In 1 specimen, a total of 3 dominant rightsided GPRAs are evident (arrows), present at the level of $\mathrm{T} 1$ $(0.371 \mathrm{~mm})$, T12 (0.319 mm), and L1 (0.240 mm).

Table 1: Distribution of GPRAs based on side and spinal level

\begin{tabular}{lcc}
\hline Spinal Level & $\begin{array}{c}\text { Left-Sided GPRA } \\
(\mathbf{2 4 / 3 6 )}\end{array}$ & $\begin{array}{c}\text { Right-Sided GPRA } \\
(\mathbf{2 5 / 3 6 )}\end{array}$ \\
\hline T9 & 2 & 3 \\
T10 & 4 & 2 \\
T11 & 2 & 3 \\
T12 & 9 & 9 \\
L1 & 5 & 6 \\
L2 & 2 & 1 \\
L3 & 0 & 1 \\
\hline
\end{tabular}

segmental ASA circulations are associated with markedly differing calibers of the AKA. In the same manner, pauci-segmental and pluri-segmental PSA circulations are associated with differing calibers of the GPRA.

A GPRA was not identified in $28 \%$ of specimens (14/50). In all the spinal cord specimens in which a GPRA was not present, the ventral distal ASA trifurcated distally into a tiny midline artery that coursed toward the filum terminale and 2 small-caliber lateral branches along the anterolateral surface of the conus, which formed termino-terminal anastomoses with the corresponding PSAs (Fig 5). Each of the 2 lateral arteries originating from the distal ASA trifurcation measured, on average, $0.35 \mathrm{~mm}$ on the right and $0.31 \mathrm{~mm}$ on the left. If the ASA did not exhibit this trifurcation branching pattern, the distal dorsal spinal cord was instead supplied by a GPRA. In the specimens in which the distal ASA did not exhibit a trifurcation pattern, the distal ASA gradually-but-drastically became diminished in caliber as it reached the conus. Careful analysis of the posterior spinal nerves in these cases established the presence of a GPRA in every case without exception.

With respect to the artery of Adamkiewicz, a left-sided vessel was present in 45 specimens and a right-sided AKA was present in 5 specimens. Of these, 6 specimens demonstrated duplicated AKAs with 3 having 2 separate AKAs, both on the left side, and 3 having bilateral AKAs (1 left and 1 right). Of the left-side duplications, 2 cases demonstrated duplicated left-sided AKAs at T8 and T12 and 1 case demonstrated duplicated T11 and T12 with leftsided origins. The bilateral duplications were present at T8 on the left and T12 on the right, T9 on the left and T10 on the right, and T11 on the left and T8 on the right. The AKA most frequently originated on the left at the level of T9 in 13 specimens and at the level of T8 in 10 specimens. The side and spinal levels of AKAs are summarized in Table 2.

The most proximal AKA was evident at the T3 level on the left, and the most distal, at the L2 level of on the left. On average, the diameter of the AKA was $0.82 \mathrm{~mm}$, with the smallest caliber AKA measuring $0.49 \mathrm{~mm}$ and the largest measuring $1.21 \mathrm{~mm}$. When 2 AKAs were present, the smallest caliber vessel measured $0.4 \mathrm{~mm}$ and the largest measured $0.79 \mathrm{~mm}$.

\section{DISCUSSION}

Spinal cord ischemia remains an infrequent-yet-devastating consequence of spinal and thoraco-abdominal surgical and endovascular procedures. Radiculomedullary arteries, which provide arterial supply to the spinal cord, are variable in location and few in number. In particular, the dominant radiculomedullary artery supplying the ASA, termed the AKA, has received extensive attention in the literature. However, the caliber of the anterior circulation with a usual ASA diameter of $0.2-0.8 \mathrm{~mm}$ and an AKA diameter of $0.5-1.0 \mathrm{~mm}^{3}$ allows these vessels to be reliably visualized via in vivo imaging studies. ${ }^{2,11,12}$ Although the anatomy of the ASA and its supplying branches has been well-studied and is currently well-understood, the more complex configuration of the paired PSAs has received much less attention, often yielding complicated, confusing, and, at times, discordant results. In particular, the smaller radiculomedullary arteries supplying the posterior spinal arteries have received scant attention. In part, the decreased attention stems from the smaller size of the posterior circulation branches, making them more difficult to detect and rendering them less consequential to ischemic deficits when occluded. The posterior spinal arteries are usually $0.1-0.4 \mathrm{~mm}$ in diameter, and the posterior radiculomedullary arteries are typically smaller. Thus, the posterior radiculomedullary arteries are rarely well-depicted in vivo during spinal angiography.

In vivo studies of the remainder of the spinal cord vasculature are extremely difficult owing to the smaller caliber of these vessels often beyond the resolution of imaging. In addition, the substantial anatomic variability of these vessels and their complex course makes their identification virtually unattainable. Nonetheless, to 


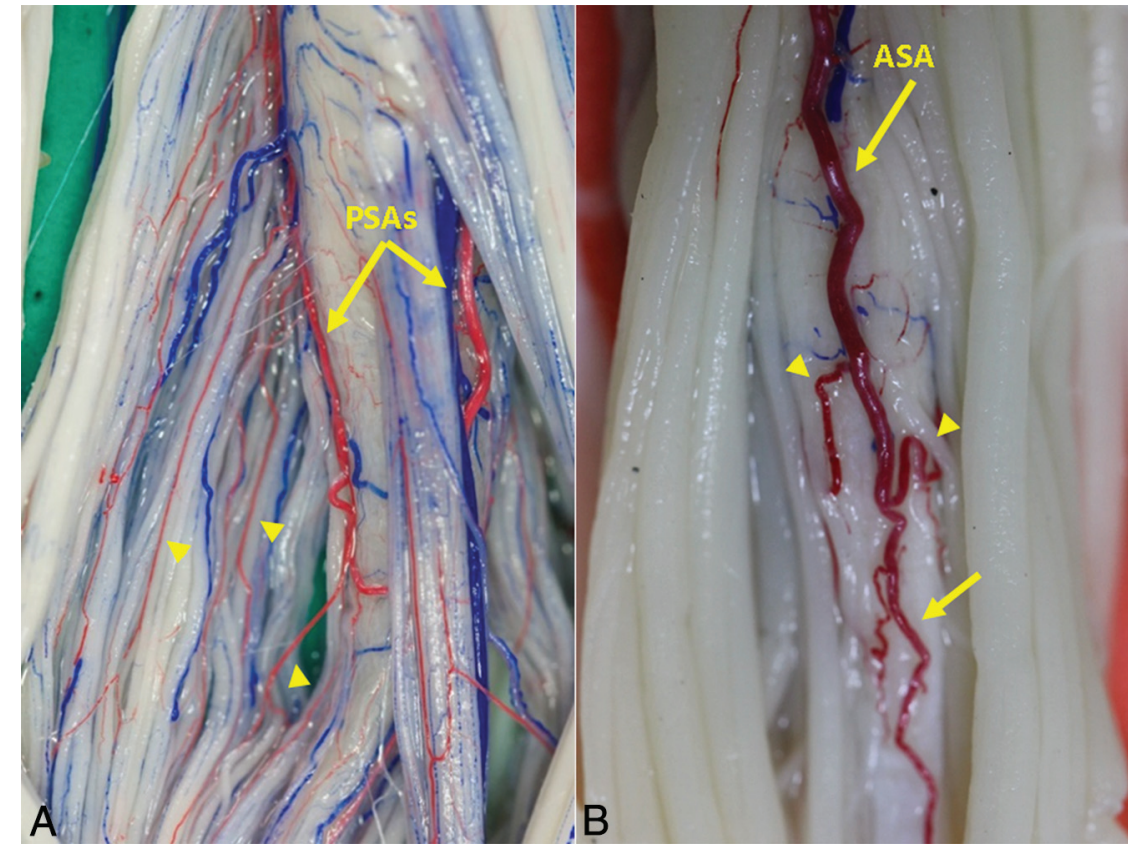

FIG 5. Absence of a GPRA. In specimen A, bilateral PSAs are evident along the dorsal aspect of the cord (A, arrows), with numerous small-caliber posterior radiculomedullary arteries supplying the left PSA (A, arrowheads). A posterior radiculomedullary artery with a dominant caliber could not be identified. No GPRA is evident in this case. In cases in which a GPRA is absent, a typical trifurcation pattern of the ASA is evident along the ventral aspect of the cord (B). The distal ASA typically trifurcates distally into a small midline artery $(B$, arrow), which courses toward the filum terminale and 2 small-caliber lateral branches ( $B$, arrowheads) along the anterolateral surface of the conus, which form termino-terminal anastomoses with the corresponding PSAs (often referred to as the basket of the conus medullaris).

Table 2: Artery of Adamkiewicz side and level of origin ${ }^{a}$

\begin{tabular}{lcc}
\hline Spinal Level & Left-Sided AKA & Right-Sided AKA \\
\hline T3 & 1 & 0 \\
T4 & 0 & 0 \\
T5 & 1 & 0 \\
T6 & 1 & 0 \\
T7 & 2 & 1 \\
T8 & 10 & 1 \\
T9 & 13 & 1 \\
T10 & 6 & 3 \\
T11 & 5 & 1 \\
T12 & 5 & 1 \\
L1 & 2 & 0 \\
L2 & 2 & 0 \\
\hline
\end{tabular}

${ }^{\mathrm{a}}$ Six of the specimens demonstrated duplicated AKAs.

interpret imaging findings with abnormally dilated branches and plan surgical or endovascular procedures, we must have a more extensive knowledge of the spinal cord vascular anatomy. Therefore, we must necessarily turn to postmortem studies to obtain information related to the small-caliber spinal cord circulation. Because postmortem studies of the spinal cord circulation are so infrequent and technically demanding, our knowledge regarding the posterior radiculomedullary arteries to this date is scant. Of those studies available in the literature, conflicting evidence and inaccuracies are not uncommon. In addition, the nomenclature for the same vessel often varies, leading to further confusion.
The results of this study demonstrate that in most individuals, there is a posterior radiculomedullary artery in the region of the lumbar spine, which distinguishes itself as the dominant arterial supply from other posterior medullary arteries due to its size. This prominent posterior artery supplying the spinal cord may be considered the GPRA, and our findings conclusively describe its presence. The definitive identification of a GPRA in $72 \%$ of our cases corroborates the disputed findings of Gillian (1958), ${ }^{13}$ Lazorthes et al (1958), ${ }^{14}$ Jellinger (1966), ${ }^{7}$ and Thron $(2016)^{3}$ and refute the findings of Corbin (1961), ${ }^{9}$ Clemens (1966), ${ }^{10}$ and Piscol (1972). ${ }^{8}$ Our study adds new information highlighting the importance of a dominant posterior radiculomedullary artery to the arterial supply of the posterior distal spinal cord.

Our results also have implications for the anatomic understanding of the arterial cruciate anastamosis (arterial basket) of the conus medullaris and its associated variations and watershed zones. ${ }^{15-17}$ As previously noted, the caudal ASA diminishes in caliber and branches into 2 small lateral branches, which curve dorsally and anastamose with the paired PSAs. In the study conducted by Rodriguez-Baeza et al (1991), ${ }^{18}$ they noted that the AKA was accompanied by a posterior radiculomedullary artery in $63 \%$ of cases. Unfortunately, they only documented the size of anterior radiculomedullary arteries and therefore failed to identify the dominant posterior radiculomedullary supply. This finding contrasts with that of Lazorthes et al (1957), ${ }^{19}$ who described a posterior radiculomedullary artery always associated with the AKA and Houdart et al $(1965)^{20}$ and Tveten (1976), ${ }^{21}$ who noted that this association was found in only one-third of cases. As noted in these previous articles, ${ }^{16,17}$ different configurations of the arterial basket have been identified. As our results indicate, the presence or absence of a GPRA correlates with different anastamotic configurations.

The substantial number of specimens examined in this study gives us confidence regarding the reliability of our vessel distribution, laterality, and diameter determinations. However, almost all anatomic specimens were from male cadavers. Therefore, the unlikely possibility that sex differences exist cannot be definitively excluded. In addition, the possibility of racial variations cannot be excluded on the basis of this study.

\section{CONCLUSIONS}

A GPRA is conclusively present in most (72\%) individuals. Understanding this intricate anatomy and its variations is critical 
for addressing vascular malformations of the spinal cord. A better understanding of the spinal cord circulation will lead to reduced risk of surgical and endovascular spinal and aortic procedures.

\section{REFERENCES}

1. Santillan A, Nacarino V, Greenberg E, et al. Vascular anatomy of the spinal cord. J Neuronterv Surg 2012;4:67-74 CrossRef Medline

2. Vargas MI, Gariani J, Sztajzel R, et al. Spinal cord ischemia: practical imaging tips, pearls, and pitfalls. AJNR Am J Neuroradiol 2015;36: 825-30 CrossRef Medline

3. Thron AK. Vascular Anatomy of the Spinal Cord. Palgrave: Macmillan; 2016

4. Etz CD, Kari FA, Mueller CS. The collateral network concept: a reassessment of the anatomy of spinal cord perfusion. $J$ Thorac Cardiovasc Surg 2011;141:1020-28 CrossRef Medline

5. Griepp RB, Griepp EB. Spinal cord perfusion and protection during descending thoracic and thoracoabdominal aortic surgery: the collateral network concept. Ann Thorac Surg 2007;83:S865-69 CrossRef Medline

6. Kadyi H. Uber die Blutgefabe des menschlichen Ruckenmarks. Lemberg: Gubrynoxicz u Schmidt; 1889

7. Jellinger K. Zur Orthologie und Pathologie der Ruckenmarksdurchblutung. Vienna: Springer Vienna; 1966

8. Piscol K. Die Blutversonrgung des Ruckenmarks und ihre klinische Relevanz. New York: Springer-Verlag; 1972

9. Corbin JL. Arteries of the spinal cord and medullary ischemic pathology. Presse Med 1961;69:1341-44 Medline

10. Clemens HJ. Beitrag des morpholegen zum problem der spinalen mangeldurchblutung. Verh Dtsch Kongr.inn. Med 1966;1059-80

11. Backes WH, Nijenhuis RJ. Advances in spinal cord MR angiography. AJNR Am J Neuroradiol 2008;29:619-31 CrossRef Medline
12. Nijenhuis RJ, Backes WH. Optimal preoperative imaging of spinal cord blood supply. AJNR Am J Neuroradiol 2009;30:E38-39 CrossRef Medline

13. Gillian LA. The arterial blood supply of the human spinal cord. $J$ Comp Neurol 1958;110:75-103 CrossRef Medline

14. Lazorthes G, Poulhes J, Bastide G, et al. Arterial vascularization of the spine; anatomic research and applications in pathology of the spinal cord and aorta (in French). Neurochirurgie 1958;4:3-19

15. Gailloud P, Gregg L, Galan P, et al. Periconal arterial anastomotic circle and posterior lumbosacral watershed zone of the spinal cord. J Neurointervent Surg 2015;7:848-53 CrossRef Medline

16. Martirosyan NL, Kalani MY, Lemole GM Jr, et al. Microsurgical anatomy of the arterial basket of the conus medullaris. J Neurosurg Spin 2015;22:672-76 CrossRef Medline

17. Rojas S, Ortega M, Rodríguez-Baeza A. Vascular configurations of anastomotic basket of conus medullaris in human spinal cord. Clin Anat 2018;31:441-48 CrossRef Medline

18. Rodriguez-Baeza A, Muset-Lara A, Rodriguez-Pazos M, et al. The arterial supply of the human spinal cord: a new approach to the arteria radicularis magna of Adamkiewicz. Acta Neurochir (Wein) 1991;109:57-62 CrossRef Medline

19. Lazorthes G, Poulhes J, Bastide G, et al. Research on the arterial vascularization of the medulla; applications to medullary pathology. Bull Acad Natl Med 1957;141:464-77 Medline

20. Houdart R, Djindjian R, Julian $H$, et al. New data on the vascularization of the dorso-lumbar spinal cord. (Radiological application and surgical interest)] (in French). Rev Neurol (Paris) 1965;112:47276 Medline

21. Tveten L. Spinal cord vascularity, I: extraspinal sources of spinal cord arteries in man. Acta Radiology Diagn (Stockh) 1976;17:1-16 CrossRef Medline 